\title{
Heterosis breeding in tomato for yield and quality contributing trait
}

\author{
PAWAN KUMAR ${ }^{1}$, RAMESH CHOUDHARY ${ }^{1}$ AND BHANWAR LAL JAT ${ }^{2}$ \\ ${ }^{1}$ Department of Agriculture, Bhagwant University, AJMER (RAJASTHAN) INDIA \\ ${ }^{2}$ Department of Agricultural Biotechnology, Bhagwant University, AJMER (RAJASTHAN) INDIA \\ Email : kripa38156@gmail.com
}

Article Info : Received : 21.07.2017; Revised : 28.08.2017; Accepted : 30.09.2017

In the present study of correlation which revealed that average fruit weight, number of fruits per plant, equatorial fruit diameter, polar fruit diameter, titratable acidity, ascorbic acid content possessed significant positive correlation with total fruit yield and days to 50 per cent flowering and days to first fruit set was having high significant negative correlation with total fruit yield. On the other hand total soluble solids content have high significant positive correlation with lycopene content, total carotenoids content, total phenol content and total antioxidant capacity and total soluble solids exerted high significant negative correlation towards titratable acidity and ascorbic acid content. This study revealed that large size tomato fruits are not just good yielder moreover, they are also nutritionally very rich in quality. Path analysis studies in this research work revealed high direct positive effect of number of fruits per plant, equatorial fruit diameter, polar fruit diameter, days to first flowering, days to first fruit set on total fruit yield and quality both. While high negative direct effect on total yield was expressed by days to 50 per cent flowering, average fruit weight, lycopene content, total carotenoids content. Hence, selection for number of fruits per plant, equatorial fruit diameter and polar fruit diameter can be effectively done for improving yield. While heterosis studies showed that cross Pusa Rohini $x$ CLNB possessed high significant SH towards days to first flowering, days to 50 per cent flowering, days to first fruit set. Arka Alok x CLNB posessed high significant BPH and SH heterosis in the desirable direction for total fruit yield, while Pusa Rohini $\mathrm{x}$ Sel-12 was having high significant standard heterosis for total soluble solids, lycopene content and total carotenoids content , respectively. On the basis of combining ability studies we were able to identify the best parents and hybrids based on GCA and SCA analysis. So on GCA basis Kashi Vishesh was found to be the best general combiner in relation to fruit yield per plant and total fruit yield whereas Sel-12 was found to be the best general combiner in relation to earliness while Pusa Rohini was found to be the best in relation to important biochemical aspects. While on SCA basis cross Arka Alok x CLNB was found to be the best specific cross combination for fruit yield per plant and total fruit yield. Whereas Pusa Rohini $x$ CLNR was found to be the best specific cross combination in relation to biochemical parameters i.e. for total soluble solids content, lycopene content, total carotenoids content, total antioxidant capacity and ascorbic acid content.

Key words : GCV, SCA, CLNB, CLNR, DUS, PPV, FRA

How to cite this paper : Kumar, Pawan, Choudhary, Ramesh and Jat, Bhanwar Lal (2017). Heterosis breeding in tomato for yield and quality contributing trait. Asian J. Bio. Sci., 12 (2) : 259-279.DOI : 10.15740/HAS/AJBS/12.2/259-279. 